\title{
Our observations with Cold Calling: patient anger and undesirable experiences
}

(Cold Calling)

\author{
Authors: \\ Prof David McD Taylor ${ }^{1,2}$ MBBS MD DRCOG MPH FACEM \\ Dr Joyce A Kant ${ }^{3}$ BBioMed MD \\ Dr Mahesha HK Dombagolla ${ }^{4}$ BMedSci MD \\ Dr Fiona WY Lai ${ }^{5}$ BBioMed MD \\ Dr Andreas Hendarto ${ }^{6}$ BBioMed MD \\ ${ }^{1}$ Director of Emergency Medicine Research, Emergency Department, Austin Hospital, \\ Heidelberg, Australia 3084 \\ ${ }^{2}$ Professor, Department of Medicine, University of Melbourne, Parkville, Victoria, Australia \\ 3052 \\ ${ }^{3}$ Intern, Eastern Health, 5 Arnold St, Box Hill, Victoria, Australia 3128 \\ ${ }^{4}$ Intern, Goulburn Valley Health, 2/2-48 Graham St, Shepparton, Victoria, Australia 3630 \\ ${ }^{5}$ Intern, Royal Melbourne Hospital, Parkville, Victoria, Australia 3052 \\ ${ }^{6}$ Intern, Bairnsdale Regional Health Service, Bairnsdale, Victoria, Australia 3875
}

\section{Corresponding Author:}

Professor David Taylor

Emergency Department, Austin Hospital

Studley Road, Heidelberg, Victoria, Australia 3084

Phone (W) +61 394964711

David.Taylor@austin.org.au

\section{Author Contributions:}

JK and DT developed the protocol for the project that this research was drawn from. DT obtained ethics committee approval. JK, FL, MD and AH collected all the data and assisted DT in its analysis and interpretation. All authors contributed to drafting and critical revision of the manuscript.

Key words: emergency department, ethics, research methods

\section{Word Count: 1492}

This is the author manuscript accepted for publication and has undergone full peer review but has not been through the copyediting, typesetting, pagination and proofreading process, which may lead to differences between this version and the Version of Record. Please cite this article as doi: $10.1111 / 1742-6723.13258$

This article is protected by copyright. All rights reserved. 


\title{
Our observations with Cold Calling: patient anger and undesirable experiences
}

(Cold Calling)

\author{
Authors: \\ Prof David McD Taylor ${ }^{1,2}$ MBBS MD DRCOG MPH FACEM \\ Dr Joyce A Kant ${ }^{3}$ BBioMed MD \\ Dr Mahesha HK Dombagolla ${ }^{4}$ BMedSci MD \\ Dr Fiona WY Lai ${ }^{5}$ BBioMed MD \\ Dr Andreas Hendarto ${ }^{6}$ BBioMed MD \\ ${ }^{1}$ Director of Emergency Medicine Research, Emergency Department, Austin Hospital, \\ Heidelberg, Australia 3084 \\ ${ }^{2}$ Professor, Department of Medicine, University of Melbourne, Parkville, Victoria, Australia \\ 3052 \\ ${ }^{3}$ Intern, Eastern Health, 5 Arnold St, Box Hill, Victoria, Australia 3128 \\ ${ }^{4}$ Intern, Goulburn Valley Health, 2/2-48 Graham St, Shepparton, Victoria, Australia 3630 \\ ${ }^{5}$ Intern, Royal Melbourne Hospital, Parkville, Victoria, Australia 3052 \\ ${ }^{6}$ Intern, Bairnsdale Regional Health Service, Bairnsdale, Victoria, Australia 3875
}

\section{Corresponding Author:}

Professor David Taylor

Emergency Department, Austin Hospital

Studley Road, Heidelberg, Victoria, Australia 3084

Phone (W) +61 394964711

David.Taylor@austin.org.au

\section{Author Contributions:}

JK and DT developed the protocol for the project that this research was drawn from. DT obtained ethics committee approval. JK, FL, MD and AH collected all the data and assisted DT in its analysis and interpretation. All authors contributed to drafting and critical revision of the manuscript.

Key words: emergency department, ethics, research methods

This article is protected by copyright. All rights reserved. 
Word Count: 1492

\begin{abstract}
Little is known about the effects of the 'cold calling' technique (telephone contact without prior warning) for patient follow up in ED research. Recently, we undertook a prospective, observational pain management study. Patients were cold called 48 hours post-discharge and surveyed regarding their pain management satisfaction. We made contact with 778 patients. Among these, we observed 12 cases of patient anger: mistaken identity, disbelief that the hospital was calling, frustration that test results and appointment times could not be provided, abuse about ED management, and outpourings of sadness. We also observed 8 cases of an undesirable experience for either the patient, their family or the caller: five patients had died (including one 'at her last moments'), precipitation of patient distress and uncomfortable situations for the caller. Given our experience, we believe that cold calling should be avoided, where possible, and other techniques (e.g. limited disclosure) considered as alternatives.
\end{abstract}

Key words: emergency department, ethics, research methods

This article is protected by copyright. All rights reserved. 


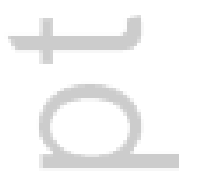

This article is protected by copyright. All rights reserved. 
A 'cold call' has been defined as a telephone call soliciting business made directly to a potential customer without prior contact or without a lead. ${ }^{1}$ While this definition is drawn from the commercial setting, the cold calling technique is employed in emergency medicine research, especially for the collection of outcome data at patient follow up. ${ }^{2}$ In general, cold calling is regarded as a less than optimal research practice and our recent experience exemplifies the reasons for this.

\section{Study description}

We undertook a prospective, observational study of patients with painful conditions in the ED of a metropolitan, tertiary referral hospital (February-May 2017, inclusive). ${ }^{3}$ The study employed the cold calling technique for all patients to collect data on patient satisfaction with their pain management. Forty-eight hours post-discharge, medical student researchers attempted to cold call all 1108 potential participants (those who appeared to meet the study entrance requirements) to obtain these outcome data. We employed this technique to minimise potential measurement bias arising from the Hawthorne Effect ${ }^{4}$, where patients may alter their responses knowing that they are being observed.

Following our standard research practice, we prospectively documented data on patient refusal, concern or complaint, including issues relating to the patients' experience with the cold call. Expression of these experiences was spontaneous and not solicited. The callers' notes relating to these calls are mostly reported verbatim although some minor paraphrasing 
has been undertaken. The study and the reporting of the observed effects of cold calling were approved by the institution's Human Research Ethics Committee (HREC).

\section{Effects on our patients}

We contacted 778 (70.2\%) of 1108 patients identified to receive a follow up cold call. Unfortunately, we observed 12 cases of patient anger during the calls (Box 1). Several patients did not believe we were calling from the hospital. There was also frustration with us not being able to provide investigation results and appointment details. In some cases, it was likely that our identity was mistaken, despite the telephone script being followed. There was one case where the patient thought the call was inappropriate and two cases associated with outpourings of anger.

We also observed eight cases of undesirable experiences during the calls (Box 2). In five cases, the patients had died. In one of these cases, the death had been very recent and in another it was imminent. In four cases, we observed substantial outpourings of grief. Although these cases did not involve angry exchanges with the caller, it seemed clear that the cold call had precipitated these incidents.

It has been reported that harm to a research participant includes, among other things, psychological harm e.g. anger and distress. ${ }^{5}$ Our study indicates that such harm was observed 
while cold calling a small number of patients. These cases, although not always accompanied by anger, were regrettable. For example, the call that was made in the 'last moments' of one patient was particularly disturbing.

Given the paucity of literature on harm observed with cold calling ${ }^{6}$ and the lack of similar incidents in our previous use of this technique ${ }^{2}$, we expected neither the patient anger nor the undesirable experiences observed. Campbell et al. ${ }^{6}$ randomised patients to receive telephone follow up either with or without prior ED consent. They reported that only $0.7 \%$ individuals from the non-consented group was displeased with receiving the call for research purposes. This proportion is smaller than ours. However, it is not reported whether they prospectively and systematically collected their data. If not, the effect of the cold calling may have been an under-estimate.

\section{Effects on our callers}

Several of the callers' notes hint at their own adverse psychological effects associated with the calls e.g. 'I was a tad traumatised after this call' and 'heart wrenching'. In addition, it is conceivable that being yelled at, or calling a patient '.. at her last moments', would also be disturbing. To our knowledge, there are no reports examining distress among cold callers undertaking medical research. However, Kjellberg et al. ${ }^{7}$, in a study of call centre workers, reported that $14 \%$ and $47 \%$ were in states of high stress/low energy (worn out) and high stress/high energy (committed under pressure), respectively. 


\section{Effects on the study methodology}

The cold calling technique may have adversely impacted upon our follow up rate. As no patient was approached in the ED, this precluded verification of the patients' current telephone number(s). It has been reported that substantial proportions of ED patients have telephone numbers that are invalid. ${ }^{8,9}$ Boudreaux et al. reported contact with $71 \%$ of patients when the telephone number was solicited by ED research personnel ${ }^{9}$ and only $42 \%$ when using numbers given during ED registration. ${ }^{8}$ However, Menchine et al. ${ }^{10}$ reported similar contact rates among patients with verified numbers (73\%) and those without (68\%). Overall, the available evidence suggests that verification of the patients' telephone number(s) results in improved contact rates.

One hundred and seven patients were found to have exclusion criteria at follow up (mostly language barriers). These patients, therefore, received a cold call unnecessarily and were exposed to risks of harm. Also, replacement patients had to be enrolled and this was associated with considerable additional resource expenditure.

\section{Balancing the risks and benefits of cold calling}

One ethical principle guiding clinical research is that of respect. In this regard, potential participants should be provided with sufficient information on the proposed research to inform their decision to participate. ${ }^{5}$ Cold calling, therefore, appears to be inconsistent with this principle as the patient will not have consented to receive the call. In most jurisdictions, however, some compromise of ethical principles may be acceptable. For 
example, a waiver of consent may be approved if the benefits of the research justify any risks associated with not seeking consent or if the research has important social value. ${ }^{5}$

We employed the cold calling technique in order to minimise potential measurement bias. However, this bias was only theoretical and there was no other reason to believe that it would substantially affect our outcomes. While the technique may or may not have improved our outcomes, we did observe evidence of patient and caller harm. Hence, the balance of risk versus benefit in our study leaned towards an excess of risk. Given this, we believe that our cold calling was not justified and that an alternative consent option should have been employed. We do not, however, conclude that cold calling is unethical per se. It could be argued that the balance would be reversed if we observed only one or two cases of patient discontent.

This report focuses on apparent negative effects observed with cold calling. We did not collect data on potential positive effects. Although speculation, it is conceivable that some patients welcomed the call if it afforded a sense of interest in their wellbeing, an opportunity to contribute to research, or simply a chance to chat. While these outcomes may be intangible, they also likely impact upon the risk versus benefit balance.

\section{Avoiding or mitigating the effects of cold calling}

Where appropriate, consent to a follow up call should be obtained and documented. This also affords the opportunity to forewarn the patient, check their telephone number(s) and the most 
suitable time to call, and to advise that the caller ID may be 'blocked', if required by the calling institution.

If such consent is either impractical or not possible, methods should be considered to advise the patient that they might receive a follow up call from the ED. This may comprise verbal advice upon registration, a leaflet given to all patients upon arrival or signage in the waiting room and ED cubicles. An alternative technique is to initiate contact prior to the follow up call e.g. by SMS, email or letter. The patients are advised to expect a call and that they have the option of declining participation at that time or by replying to the message.

For some studies, a technique of 'limited disclosure' about the aims and methods of the research may be justifiable. ${ }^{5}$ This is because the aims cannot be achieved if they are fully disclosed e.g. some studies of behaviour.

If cold calling is to be employed, the study should be designed with an expectation of some patient anger and grief. Consideration should be given to interview training that incorporates empathy and conflict resolution techniques, the provision of advice and information, and a means for appropriate referral for ongoing support. Interview training should be informed by the techniques employed widely by call centres. Such training is likely to be of particular importance for inexperienced researchers, as in our study. Furthermore, for medical students, it may afford valuable skills for future patient interactions but the students should be advised of the potential risks and allowed to make an informed decision regarding their participation. 


\section{Conclusion}

Our experience with cold calling was sobering and our patients' responses are a salient reminder that their journey does not end at ED discharge. Although we conclude that the technique was likely not justified, this conclusion is made with limited information on the true extent of the inherent risks and benefits. Furthermore, although unfortunate incidents were observed at follow up, we cannot conclude that cold calling was the cause. To further explore this issue, we recommend prospective, systematic data collection on variables that might be impacted upon by cold calling. A clinical trial could be considered where patients are randomised to consent to follow up or a cold call. The trial would allow a comparison of both positive and negative effects at follow up, patient satisfaction with their follow up allocation status and any impact upon the trial outcomes. While the ethics surrounding such a trial may be contentious, it may provide a valuable insight into this poorly explored issue.

This article is protected by copyright. All rights reserved. 


\section{Acknowledgements:}

There are no acknowledgements.

This study was unfunded.

There are no competing interests to declare.

All data from this sub-study is reported in Box 1 and 2.

This article is protected by copyright. All rights reserved. 


\section{REFERENCES}

1. Merriam-Webster. An Encyclopædia Britannica Company. 'Cold Call'. Available from URL: https://www.merriam-webster.com/dictionary/cold\%20call Accessed October 22, 2018

2. Taylor DMcD, Grover Johnson O, Lee M, Ding J-L, Ashok A. The effect of provision of pain management advice on patient satisfaction with their pain management: a pilot, randomized, controlled trial (pain advice trial). Emerg Med J 2016; 33: 453-457

3. Kant JA, Dombagolla MHK, Lai FW, Hendarto A, Taylor DMcD. Analgesia in the Emergency Department: Why is it not administered? Emerg Med $J$ Published online ahead of print. doi:10.1136/emermed-2018-207629

4. Chen LF, Vander Weg MW, Hofmann DA, Schacht Reisinger H. The Hawthorne Effect in Infection Prevention and Epidemiology. Infect Control Hosp Epidemiol 2015; 36: 1444-1450

5. National Health and Medical Research Council, Australian Government. National Statement on Ethical Conduct in Human Research (2007) - Updated May 2015. Available from URL: https://www.nhmrc.gov.au/guidelines-publications/e72 Accessed August 21, 2018

6. Campbell SG, McCarvill EM, Magee KD, Cajee I, Crawford M. The consent and prescription compliance (COPRECO) study: Does obtaining consent in the emergency department affect study results in a telephone follow-up study of medication compliance? Acad Emerg Med 2008; 15: 932-938

This article is protected by copyright. All rights reserved. 
7. Kjellberg A, Toomingas A, Norman K, Hagman M, Herlin RM, Tornqvist EW. Stress, energy and psychosocial conditions in different types of call centres. Work 2010; 36: 9-25

8. Boudreaux ED, Ary RD, St. John B, Mandry CV. Telephone contact of patients visiting a large municipal emergency department: can we rely on numbers given during routine registration? J Emerg Med 2000; 18: 409-415

9. Boudreaux ED, Clark S, Camargo CA Jr et al. Telephone follow-up after the emergency department visit: experience with acute asthma. Annals Emerg Med 2000; 35: 555-563

10. Menchine M, Oberfoell S, Schriger S, Walker C, Riddell J, Arora S. Improving telephone follow-up for patients discharged from the emergency department: Results of a randomized controlled trial. Acad Emerg Med 2013; 20: 456-462

This article is protected by copyright. All rights reserved. 
Box 1. Patient anger associated with the cold calls

This article is protected by copyright. All rights reserved. 
Got very defensive when I asked her to confirm her details. She said I should know them already and thus there should be no need to confirm if I really was calling from the [hospital].

Did not believe that I was from the [hospital]. Wanted to know how I got his private number.

Yelled at in foreign language. I believe she misidentified me as a telemarketer.

The patient doubted whether I was really calling from the [hospital] when I was unable to provide her with her appointment details. I explained that I was not permitted to and she got quite annoyed and frustrated at me.

[The patient] was supposed to have an outpatient appointment but the [hospital] hadn't contacted him. Got upset at me because I couldn't give him any information about it.

Forgot to block [my] caller ID. Multiple calls to my phone with an angry, elderly lady yelling 'Who you are? Where my blood result?"

Got angry at me for calling after hours. Refused to complete survey. Called me back to clarify why I was doing a survey and agreed to complete it after all.

Patients are in general suspicious when I say the interview will take around 60 seconds. When it actually took around that time, patient was convinced he had answered the questions wrong. "Did I answer the questions wrong? I must have answered them wrong."

Gentleman answered and [when] I introduced myself, he shouted something and hung up.

Daughter picked up and was a bit prickly about why [I was] calling. [She] explained that her mother had just been transferred to Palliative Care today and that we shouldn't be calling.

Wanted to complain about the way she was treated and managed in the ED. Yelled at me and became very frustrated about her ill treatment. Wanted me to pass along her feedback.

The patient was disgusted with the way the [hospital] treated him and got his diagnosis wrong. He'd called up 'patient experiences' multiple times, however everyone kept 'fobbing him off.' Wanted someone at the [hospital] to invite him over for a cup of tea and a chat. Threatened to take legal action and call up [the media]. After the injustices ..... he even considered killing himself by jumping into a lake. When I explained to him .... that I was only a student and there was nothing I could do he said "You're fobbing me off just like the others." .......I was a tad traumatised after this call! 


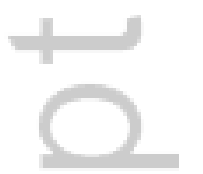

This article is protected by copyright. All rights reserved. 
Box 2. Undesirable experiences associated with the cold calls

Tried calling up a middle aged woman. Her husband picks up. I asked him if his wife can come to the phone and he says she is unable to. I then ask him if she'll be available later on. He replied with "I don't think so. She's at her last few moments."

I tried calling up an elderly gentleman only to have his grieving wife pick up and tell me that he died the day before.

The son of the patient answered. Explained that his mother had passed away a month ago which would have been around the time this patient was recruited.

[NOTE: Two other patients died prior to the cold call. For these, no specific notes were made by the callers.]

[The patient] burst into tears over the phone because she received inadequate pain management from the ED. [She] was still in a lot of pain. This was one long phone call.

[The patient is] still experiencing pain and does not know how to seek help. Feels hopeless and kept seeking my advice as to how he should manage his pain.

[The patient] tells me about this chronic pain and his loneliness. Talks about his alcoholic abuse and smoking but would like to quit. Seeks help from me and doesn't believe the GP can do anymore for him.

We had a very long (and quite saddening) conversation about how she had to make a several-hour-long trip to [the hospital] from [another town] because they thought that she had an infection in her ascitic tap - when, in fact, she didn't. And it took [the hospital] several more hours to inform her, before she had to drive back [home] for several more hours. She was due for a liver transplant too. Heart-wrenching. 


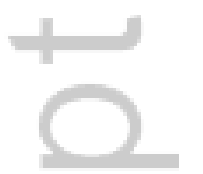

This article is protected by copyright. All rights reserved. 


\section{University Library}

\section{- M M N E R VA A gateway to Melbourne's research publications}

Minerva Access is the Institutional Repository of The University of Melbourne

Author/s:

Taylor, DM;Kant, JA;Dombagolla, MHK;Lai, FWY;Hendarto, A

Title:

Our observations with cold calling: Patient anger and undesirable experiences

Date:

2019-04-01

Citation:

Taylor, D. M., Kant, J. A., Dombagolla, M. H. K., Lai, F. W. Y. \& Hendarto, A. (2019). Our observations with cold calling: Patient anger and undesirable experiences. EMERGENCY MEDICINE AUSTRALASIA, 31 (2), pp.283-286. https://doi.org/10.1111/1742-6723.13258.

Persistent Link:

http://hdl.handle.net/11343/285471 